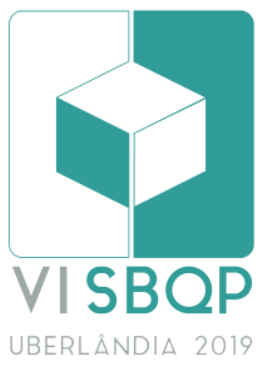

\title{
SEGMENTAÇÃO NA ATUAÇÃO DAS EMPRESAS DE ARQUITETURA NO MUNICÍPIO DE SÃO PAULO
}

\author{
TREVISAN, Ricardo Marques \\ Universidade de São Paulo, e-mail: ricardo.trevisan@usp.br \\ BARROS, Gil \\ Universidade de São Paulo, e-mail: gil.barros@usp.br \\ ONO, Rosária \\ Universidade de São Paulo, e-mail: rosaria@usp.br
}

\begin{abstract}
RESUMO
Este diagnóstico da atuação de empresas de arquitetura e urbanismo no território do município de São Paulo constitui etapa inicial da pesquisa para doutorado do primeiro autor, cujo objeto final é o plano de negócios da atuação profissional do arquiteto. Vários aspectos encontrados corroboram a hipótese de que existem, no mínimo, limites para a atuação generalista do arquiteto e urbanista, e parece apontar para a segmentação de sua atuação profissional. A hipótese supõe ser muito difícil uma empresa do ramo conseguir atuar de forma generalista, e que os escritórios de arquitetura tendem a se especializar em segmentos específicos para otimizar seus resultados, ganhar eficiência operacional e construir uma imagem que viabilize sua longevidade. Foi realizado um estudo amostral de empresas ativas e atuantes no município de São Paulo em 2018, e foram impostos critérios rigorosos de validação de cada dado. As conclusões indicam que nem todas as empresas de arquitetura atuam sequer nos grupos de atividades a que 0 arquiteto e urbanista está habilitado, e que essas costumam atuar com diferentes grupos, naturezas, setores de clientes; que oferecem diferentes produtos principais a diferentes mercados, possuem diferentes modelos de negócios, e selecionam nichos de atuação entre clientes privados.
\end{abstract}

Palavras-chave: Arquitetura e urbanismo, Segmentação, Prática profissional.

\begin{abstract}
This diagnosis of architecture and urbanism firms performance in the city of São Paulo constitutes the initial stage of the research for the first author's doctorate degree, whose final objective is to build a business plan for architects. Several findings corroborate the hypothesis that there are at least limits to the generalist profile of architects, and it seems to point to the segmentation of his professional practice. The hypothesis assumes that it is very difficult for a company in the field to be able to act in a generalist way, and that architecture offices tend to specialize in specific segments to optimize their results, gain operational efficiency and build an image that enables their longevity. A sample study of active and acting companies was carried out in the city of São Paulo in 2018, with strict criteria for data validation. The conclusions indicate that not all architecture companies act even in the groups of activities to which the architect and urban planner is licensed, and that these usually act in different groups, natures, and clients profiles; offer different main products to different markets, have different business plans, and select niches of action among private clients.
\end{abstract}

Keywords: Architecture and urbanism, Segmentation, Professional practice.

\section{PRIMEIRA EVIDÊNCIA DE SEGMENTAÇÃO}

Até o momento em que a pesquisa foi fechada (dezembro de 2017), havia 22.147 empresas de arquitetura e urbanismo no Brasil, aproximadamente uma

TREVISAN, R. M.; BARROS, G.; ONO, R. Segmentação na atuação das empresas de arquitetura no município de São Paulo. In: SIMPÓSIO BRASILEIRO DE QUALIDADE DO PROJETO NO AMBIENTE CONSTRUÍDO, 6., 2019, Uberlândia. Anais... Uberlândia: PPGAU/FAUeD/UFU, 2019. p. 222-230. DOI https://doi.org/10.14393/sbqp19022. 
empresa para cada sete arquitetos e urbanistas. Quando o Anuário 2018 revela o número total de atividades registradas em 2017, surge o primeiro indício de segmentação da atuação profissional do arquiteto e urbanista. Separadas pelos sete grupos de atividades possíveis, $85 \%$ daquelas registradas em 2017 concentram-se nos dois primeiros grupos, projeto e execução.

\section{Quadro 1 - Atividades de Arquitetura e Urbanismo realizadas no Brasil em 2017}

\begin{tabular}{|c|c|c|}
\hline Grupo de Atividades & percentual & Quantidade \\
\hline Projeto & $52,54 \%$ & 761.314 \\
\hline Execução & $33,13 \%$ & 480.011 \\
\hline Gestão & $2,25 \%$ & 32.577 \\
\hline Meio ambiente & $1,33 \%$ & 19.212 \\
\hline Atividades especiais & $10,14 \%$ & 146.969 \\
\hline Ensino e pesquisa & $0,03 \%$ & 493 \\
\hline $\begin{array}{c}\text { Engenharia de segurança do } \\
\text { trabalho }\end{array}$ & $0,57 \%$ & 8.315 \\
\hline
\end{tabular}

Fonte: Anuário 2018 (CAU/BR)

Olhando estes grupos em detalhe, são identificadas inúmeras atividades praticadas em 2017 por um número inferior ao número de empresas (e muito inferior ao número de arquitetos e urbanistas). Mesmo no grupo de atividades de projeto, mais da metade $(6 / 11)$ das atividades não atinge nem o número de empresas do ramo no país. Se fosse verdadeira a hipótese alternativa (de que os arquitetos e urbanistas têm uma atuação generalista, abrangendo todas as suas possibilidades de trabalho), seria de se esperar que uma boa parte das atividades possíveis de serem desenvolvidas por este profissional apresentasse um número de registros emitidos pelo menos em número igual ao número de empresas. Há duas lógicas para isto:

a) dificilmente uma empresa, que costuma ter mais de um profissional quando assim se constitui de fato sem ser empresa individual, emitiria apenas um registro em diversas atividades dentro de um ano; e

b) cada atividade desenvolvida pode ter a atuação de mais de um profissional pessoa física, portanto uma única atividade de uma empresa em muitos casos teria mais de um registro emitido.

Em outras palavras, mesmo que cada empresa possuísse apenas um profissional e fizesse apenas um registro para cada atividade desenvolvida no ano de 2017, ainda assim estes dados apontariam para uma atuação segmentada em nichos, e não generalista.

Portanto, caminhando para um cenário muito mais provável, de que cada empresa possui, em média, mais de um profissional, e que cada tipo de atividade desempenhada resulta, em média em mais de um registro no ano, esta constatação fica ainda mais forte.

Desconsiderando as atividades de Ensino, Pesquisa e Exercício de Cargo e Função (grupo de atividades de Engenharia de Segurança do trabalho não foi considerado por exigir formação complementar específica.), há 42 atividades possíveis de serem exercidas e documentadas por qualquer arquiteto $e$ urbanista formado e atuante no território nacional brasileiro e submetido à 
legislação do país. Os dados do Anuário denunciam que 73,8\% das atividades possíveis foram registradas em número inferior ao total de empresas de arquitetura e urbanismo abertas no país em 2017, portanto em número muito inferior ao total de profissionais de arquitetura e urbanismo habilitados na mesma época. Apenas $26,2 \%$ das atividades tiveram uma quantidade de registros que supera o número de empresas do setor. Se considerarmos que cada empresa pode ter emitido mais de um registro para a mesma atividade (pois cada pessoa física emite um registro diferente), e que uma mesma empresa provavelmente emitiu, em média, mais de um registro de mesmo tipo de atividade em 2017, é bastante difícil argumentar que a atuação do arquiteto e urbanista seja generalista e não se concentre em nichos de mercado.

\section{ESTUDO AMOSTRAL}

\subsection{Desenho do estudo}

Investigamos outras possibilidades de segmentação (como variáveis geográficas) de empresas de arquitetura e urbanismo através da análise de uma amostra aleatória probabilística de empresas com atuação neste ramo de atividade no território do município de São Paulo (SP).

O procedimento de coleta foi estabelecido através de consulta aos mecanismos de busca Google Internet e Google Mapas na internet, com os termos "empresas de arquitetura e urbanismo em São Paulo SP" e "escritórios de arquitetura e urbanismo em São Paulo SP". Os critérios de aceitação foram:

Endereço: consideramos o informado pela empresa. $\mathrm{Na}$ falta desta informação, consideramos o que a empresa forneceu ao mecanismo de busca do Google, desde que confirmado em outras fontes de informação, tais como a Junta Comercial, o informado pela empresa na rede profissional Linkedln ou informado por clientes ou fornecedores.

Porte, medida de acordo com o critério do Censo realizado pelo CAU/BR em 2013: consideramos sempre o número de pessoas trabalhando na empresa que a) a própria empresa declara em sua página na internet, b) seus integrantes declararam haver na empresa, c) contagem de pessoas que declaram atualmente trabalhar na empresa na rede social profissional Linkedln. Só foram contados dados recentes (última atualização com menos de seis meses). Foram descartados os dados que afirmam ter trabalhado na empresa no passado ou apenas prestar serviços. Consideramos apenas aquelas na qual declarem trabalhar pelo menos duas pessoas. Só foram consideradas aquelas empresas compostas por apenas duas pessoas se a página da empresa na internet se apresente de fato como uma empresa (Pessoa Jurídica).

Tipo de cliente Pessoa Física ou Jurídica: coletamos a informação de clientes atendidos na página da empresa na internet, considerando válidos: apresentação direta dos clientes da empresa, portfolio, descrição de atividades desenvolvidas, descrição da própria empresa.

Tipo de cliente Público ou Privado: informação de clientes atendidos na página da empresa na internet, como no item anterior.

Principal produto oferecido: observamos as várias possibilidades de produto principal que surgiram na amostra. Foram obtidos: Plano Diretor, Projeto de 
Edificações, Consultoria, Paisagismo, Restauro, Projetos Urbanos, Estudo de Viabilidade, Interiores, Obras. Foram observados a oferta de valor na página da empresa e perfis oficiais na rede social profissional Linkedln). Para empresas que ofertam mais de um tipo de produto, consideramos: a) o produto ofertado na página inicial, b) aquele com destaque nas demais páginas, c) o predominante no portfolio.

Conceito do modelo de negócios: observamos as várias possibilidades de oferta de valor que surgiram na amostra, a partir de portfólio, casos apresentados, descrição de serviços e de relacionamento com o cliente.

Tipos de atividades desenvolvidas: coletamos os tipos de serviços oferecidos e declarados pela empresa na página da empresa na internet.

Tipos de clientes empresariais, entre os mais recorrentes na amostra: coletamos as informações sobre clientes atendidos conforme declaradas pela empresa na internet. O critério foi sempre o tipo de serviço prestado, e não a atividadefim da empresa cliente.

Se qualquer um desses critérios não fosse cumprido ou a informação não estivesse clara, o dado era descartado. Coletamos mais de 550 elementos que, quando testados frente aos critérios de validação de cada elemento, foram reduzidos a 420 elementos. Páginas de empresas no Facebook só foram consideradas como páginas de empresas quando continham as informações mínimas definidas para este estudo, e desde que fossem também confirmadas por outras fontes, como páginas no Linkedln de outros colaboradores, empresas, clientes e fornecedores. A mesma lógica foi aplicada às páginas de empresas no Linkedln.

\subsection{Tamanho da amostra}

O número de elementos da amostra (tamanho da amostra) pode ser determinado pela expressão derivada dos experimentos Bernoulli (PINHEIRO et alii, 2004, p.103; BOTTER et alii, 1996, p.125):

$$
\mathrm{n}=0,25(\mathrm{z} / \mathrm{e})^{2}
$$

onde, $\mathrm{n}$ = número de elementos (também entendidos como observações ou dados amostrais);

$Z$ = desvio-padrão selecionado na curva normal padrão em função da representatividade desejada do universo de estudo, ou seja, é o intervalo, índice ou índice de confiança que mostra o quanto é possível confiar nos resultados (PINHEIRO et alii, 2004, p.101);

e = margem de erro, também entendida como a tolerância em relação aos resultados da pesquisa.

Apesar de PINHEIRO et alii (2004, p.101) afirmarem que "se for uma pesquisa da área de ciências sociais, cujo único objetivo é descobrir uma tendência de cunha acadêmico, é factível utilizar um índice de confiança de 68\%", optamos por maior rigor em nosso estudo, alinhando este a outros trabalhos científicos e a pesquisas mercadológicas, e elevamos 0 índice de confiabilidade para $95 \%(Z=1,96)$.

A pesquisa em mecanismos de busca nos resultou mais de 500 elementos, dos quais obtivemos dados suficientes para sua inclusão no estudo de 420 deles. 
Assim sendo, nossa margem de erro ficou dentro do critério científico aceito de $5 \%$ :

$$
\begin{gathered}
\text { n mínimo }=0,25(1,96 / 0,05) 2=385 \text { elementos } \\
e=1,96 /\left(2 \times 420^{0,5}\right)=0,0478=4,78 \%
\end{gathered}
$$

\section{OUTRAS EVIDÊNCIAS DE SEGMENTAÇÃO}

\subsection{Produto principal}

Foram observadas as ofertas de serviços via internet (página da empresa na internet e perfis oficiais das empresas na rede social profissional Linkedln). Para empresas que ofertam mais de um tipo de produto, consideramos como produto principal (em ordem decrescente): a) o produto ofertado na página inicial (splash screen), b) o produto que tem destaque nas demais páginas, c) o produto predominante no portfolio da empresa.

A amostra também demonstra que o projeto de arquitetura, apesar de ser o produto principal mais recorrente, não chega a ser a oferta principal em nem metade das empresas encontradas $(48,6 \%$ do total). Mesmo se somarmos a segundo produto principal (Arquitetura de Interiores, $37,6 \%$ do total), essas duas ofertas cobrem $86 \%$ das empresas encontradas - ou seja, mais de $13 \%$ das empresas de arquitetura não colocam estes serviços tradicionais como sua oferta principal. Listamos abaixo os percentuais dos produtos principais encontrados na amostra:

- Projeto de arquitetura: $48,7 \%$

- Arquitetura de interiores: $37,6 \%$

- Consultoria: $4,6 \%$

- Paisagismo: 3,4\%

- Obras: $2,9 \%$

- Projetos urbanos: $1 \%$

- Plano diretor municipal: 0,7\%

- Projeto de restauro: 0,7\%

- Gerenciamento: 0,7\%

- Estudo de viabilidade: $0,5 \%$

É importante lembrar que estas são as ofertas principais das empresas. Não significa necessariamente que não atuem com outros serviços também. Entretanto, o fato da oferta principal se diversificar aponta para a segmentação da atuação profissional. Outro dado de destaque é que quatro empresas da amostra (1\%) não realizam nenhum tipo de projeto.

\subsection{Atividades}

Ao levantar um quantitativo de empresas que atuam em cada categoria de atividades percebemos sinais de especialização na atuação dos escritórios de arquitetura e urbanismo. Mesmo o grupo de atividades de projeto, que inclui atividades usuais desempenhadas por arquitetos como projetos de edificações e projetos urbanos, não teve $100 \%$ de atuação na amostra. No 
grupo Execução, atuam 19,3\% das empresas coletadas; no grupo Gestão, 42,4\%; no grupo Meio Ambiente, 16\%; no grupo Atividades Especiais, 20,5\%.

\subsection{Grupos de clientes}

Em suas ofertas, quase $20 \%$ das empresas da amostra não informaram o atendimento a pessoas físicas, três empresas $(0,7 \%)$ não informaram atender a qualquer tipo de cliente privado, e apenas $29,8 \%$ informam que prestam serviços ao poder público. Os defensores da hipótese de atuação generalista poderiam alegar que apenas uma parte dos escritórios atendem o poder público por haver algum tipo seleção por este tipo de cliente - licitação ou concursos, por exemplo. Entretanto, quando esclarecemos que o critério utilizado foi o serviço prestado, e não o contrato firmado ou a remuneração auferida, isso significa que quando a empresa participa de concursos públicos, mesmo que não tenha sido premiada, foi considerada. Portanto, identificado o projeto apresentado para o júri do concurso no portfolio da empresa, este é considerado um serviço prestado (pois o poder público teve o produto à sua disposição). Assim sendo, percebe-se que praticamente $70 \%$ das empresas sequer se interessaram em tentar atender ao cliente do segmento governo, demonstrando que nem todo escritório de arquitetura tem as mesmas preferências quanto aos possíveis clientes prospectados.

Para cada elemento da amostra, contamos os tipos de clientes da iniciativa privada atendidos. Os grupos mais recorrentes foram: Incorporadoras (atendidas por $28,6 \%$ dos escritórios), Indústrias $(23,1 \%)$, Varejo comercial $(70,2 \%)$, Hospitais $(7,9 \%)$ e Hotéis $(14,5 \%)$.

\subsection{Porte}

A amostra coletada demonstra outras evidências de segmentação da forma de atuação profissional do arquiteto e urbanista, além da primeira obtida do Anuário 2018 (CAU, 2018). A segunda evidência advém da variedade no porte das empresas:

- Microempresa (<10 pessoas): 320 (76,2\%)

- Pequena empresa (de 11 a 99 pessoas): 95 (22,6\%)

- Média empresa (de 100 a 499 pessoas): 4 (1\%)

- Grande empresa (a partir de 500 pessoas): 1 (0,2\%)

Este dado demonstra variedade na forma de atuação do arquiteto, pois não encontramos qualquer correlação entre o porte da empresa e sua visibilidade ou tempo de existência. Aparentemente, existem diversos formatos e estratégias de atuação, o que gera diversidade no tamanho das empresas e no número de colaboradores.

A hipótese alternativa à da segmentação da atuação do arquiteto e urbanista (da atuação generalista) diria que os escritórios buscam um mesmo objetivo em termos de porte de empresa ideal - provavelmente seria a maior possível, seguindo a lógica de que o sucesso profissional promove o crescimento do patrimônio líquido (equity) da empresa. Entretanto, na amostra coletada, é recorrente os escritórios de arquitetura se apresentarem como uma "dissidência", ou seja, uma subdivisão (split-off) de outro escritório mais antigo. Inclusive, em todos os casos em que isto ocorreu nesta amostra, o novo escritório cita a empresa da qual se destacou como uma referência de 
reputação ou qualidade. Ou seja, podemos inferir, a partir desta observação, com boa dose de segurança, que existem outros fatores, possivelmente sociais, econômicos ou de natureza pessoal, que conduzem a atuação profissional a um conjunto de empresas de porte diversificado.

\subsection{Conceito da empresa}

O levantamento de elementos da amostra demonstrou que existe mais uma variável independente a ser considerada: forma de construção de valor no modelo de negócios. Obviamente não estamos falando do conceito financeiro da palavra valor, mas de seu entendimento estratégico, muito utilizado pelo marketing ou modelagem de negócios ou planejamento estratégico. Trata-se daquilo pelo qual o consumidor tem interesse suficiente em obter a ponto de estar disposto a abrir mão de recursos financeiros, tempo, ou energia para obter.

É tão importante que se apresenta como elemento principal da Teoria Geral da Administração desde seu princípio (MAXIMIANO, 2006). Henry Fayol propôs inclusive que a empresa é um sistema racional de regras e de autoridade com o objetivo primário de fornecer valor. O economista Jean Baptiste Say, no Tratado de economia política de 1888, associou o conceito aos empreendedores, dizendo que estes podem alterar os recursos econômicos de uma área de baixa produtividade, transformando-a em região de produtividade e lucratividade elevadas, quando se cria valor. BESANKO e colegas (2004) associam a capacidade de criação de valor à vantagem competitiva da empresa, e declaram que negócios mais bem-sucedidos na criação de valor que seus concorrentes ocupam uma posição de vantagem no mercado.

Continuando com estes autores, o consumidor só compraria um determinado produto (bem ou serviço) se o valor percebido (associado a benefícios identificados) fosse maior ou igual ao seu preço. Quando for maior que o preço, este excedente é conhecido como o excedente do consumidor. $\mathrm{E} O$ valor percebido é a máxima disposição do consumidor a pagar. Assim, a máxima disposição a pagar é o preço pelo qual o consumidor é indiferente entre comprar o produto e continuar sem ele - o que demonstra que esta é uma variável que muda de consumidor para consumidor, pois assim se comportaria o valor percebido.

HIT, IRELAND e HOSKISSON (2008) definem competitividade estratégica como aquela obtida quando a empresa consegue formular e implantar com sucesso uma estratégia de criação de valor. Colocam que as características de desempenho de um determinado produto e os atributos pelos quais os clientes estão dispostos a pagar conformam o valor criado pelo processo produtivo da empresa. Este conceito é, portanto, diverso do conceito de preço, pois seria definido em momento anterior à fixação deste último. FERREIRA, REIS, SERRA (2010), ao tratar da importância do marketing para empreendedores, defendem que o negócio deve ser definido em termos de valor oferecido.

É essencial notar que a Teoria Geral da Administração coloca o valor como elemento ofertado, sentido inverso do preço, pois este último é cobrado do cliente. Os mesmos autores ressaltam que o valor do produto (bem ou serviço) está nos benefícios ou na satisfação que proporciona; é necessário pensar além do produto tangível, situação em que o produto oferecido é o reflexo de 
como a empresa se vê: a que necessidades atende, que grupos de consumidores procura captar, e os meios para satisfazer a essas necessidades.

É crucial entender onde é que o cliente vê o valor. Assim sendo, o desafio da política de preços da empresa é estabelecer um expressão quantitativa do valor do produto para o consumidor, principalmente porque: a) se o preço for inferior ao que o consumidor está disposto a pagar, lucros potenciais estarão sendo sacrificados, e b) se o preço for superior à disposição a pagar, a venda não acontece. Dentro dessa lógica, os preços dos competidores necessariamente estarão dentro de uma faixa estabelecida por: a) um preço mínimo estabelecido pelo custeio (custos mais despesas), abaixo do qual não existe lucro, e b) um preço máximo, estabelecido pelo valor percebido pelo cliente, acima do qual o consumidor não vê vantagem na compra.

Ao tratar do comportamento do consumidor, SOLOMON (2008) afirma que as sensações ou atitudes gerais que o cliente tem após a aquisição do produto determinam o nível de satisfação do consumidor pós-compra, e o que as pessoas esperam é a combinação de qualidade e valor. DORNELAS e colegas (2017) encerram nossa enumeração tratando especificamente do modelo de negócios, segundo os quais é a explicação de como uma empresa funciona e cria valor. Permite, segundo eles, entender como a empresa produzirá retorno, qual será seu modelo de receita, e como vários processos se relacionam para atingir o objetivo, gerando valor aos clientes.

Tendo este conceito clarificado, é possível perceber, ao observar os elementos de nossa amostra, que os escritórios de arquitetura oferecem diferentes tipos de valor ao mercado. Uma atuação generalista do arquiteto e urbanista ofereceria, se não valores similares, pelo menos categorias de valor aproximadas ao seu mercado de atuação.

Entretanto, ao coletar esta amostra, percebemos pelo menos três tipos distintos de oferta de valor construídos sobre três categorias diferentes de modelos de negócios: a) um modelo de negócios que oferece como valor principal a singularidade de projeto de arquitetura e urbanismo como fator crítico de sucesso (o qual denominamos conceito autoral); b) um modelo de negócios que oferece como valor principal um produto diferente do autoral, construído com processos internos, como fator crítico de sucesso lo qual denominamos operacional), caracterizado, entre outros fatores, pela rigidez em seus processos internos; c) um modelo de negócios que oferece como valor principal o suporte a processos ou ao modelo de negócios de terceiros como fator crítico de sucesso (o qual denominamos apoiador), caracterizado, entre outros fatores, pela flexibilidade em seus processos internos.

São três formas distintas encontradas pelos escritórios de arquitetura para produzir e entregar valor a seus clientes, portanto três formas distintas de estratégias, comunicação com o mercado, posicionamento, precificação e de competitividade, de acordo com a ótica dos autores aqui citados. Assim sendo, evidenciam e corroboram a hipótese de que a atuação do profissional da arquitetura e urbanismo possui algum grau de segmentação, no mínimo em três classes claramente observáveis de modelos de negócios.

\section{CONCLUSÕES OU CONSIDERAÇÕES FINAIS}

O número de registros emitidos por grupos de atividades indica que nem todas as empresas de arquitetura atuam sequer nos grupos de atividades a que 0 
profissional está habilitado. Considerar que uma empresa dificilmente emitirá um único registro em todo o seu tempo de atividade reforça ainda mais esta percepção. As informações autodeclaradas pelas empresas em suas próprias páginas da internet indicam que estas costumam atuar com diferentes grupos, naturezas e setores de clientes. Estas mesmas informações mostram diferentes produtos principais oferecidos ao mercado, e seleção de nichos de atuação. Estes indícios no mínimo limitam a tese de atuação do arquiteto em todo o seu espectro de possibilidades de trabalhos profissionais. $O$ único aspecto em que não foram encontrados indícios de segmentação na atuação das empresas de arquitetura e urbanismo foi o geográfico no município de São Paulo (SP).

\section{REFERÊNCIAS}

BESANKO, David et alii. A economia da estratégia. 3. ed. Porto Alegre:

Bookman, 2004.

BOTTER, Denise A.; PAULA, Gilberto A.; LEITE, José G.; CORDANI, Lisbeth K. Noc,ões de estatística. São Paulo: Instituto de Matemática e Estatística da Universidade de São Paulo, 1996.

CONSELHO DE ARQUITETURA E URBANISMO DO BRASIL. Anuário 2018. Volume 2, n. 1. Brasília: CAU/BR, 2018.

DORNELAS, José; BIM, Adriana; FREITAS, Gustavo; USHIKUBO, Rafaela. Plano de negócios com o modelo Canvas: guia prático a partir de exemplos. Rio de Janeiro: LTC, 2017.

FERREIRA, Manuel Portugal; REIS, Nuno; SERRA, Fernando Ribeiro. Marketing para empreendedores e pequenas empresas. São Paulo: Atlas, 2010.

HIT, Michael A.; IRELAND, R. Duane; HOSKISSON, Robert E. Administração estratégica. Competitividade e globalização. 2. ed. São Paulo: Cengage Learning, 2008.

MAXIMIANO, Antonio Cesar Amaru. Teoria geral da administração. São Paulo: Atlas, 2006.

PINHEIRO, Roberto M.; CASTRO, Guilherme C.; SILVA, Helder H.; NUNES, José Mauro G. Comportamento do consumidor e pesquisa de mercado. Rio de Janeiro: Editora FGV, 2004.

SÃO PAULO (ESTADO). SECRETARIA DOS TRANSPORTES METROPOLITANOS. Pesquisa Origem e Destino 2007. Região Metropolitana de São Paulo. Síntese das Informações. Pesquisa Domiciliar. Diretoria de Planejamento e Expansão dos Transportes Metropolitanos. São Paulo: Governo do Estado de São Paulo, 2008.

SEBRAE (Org.). Anuário do trabalho na micro e pequena empresa: 2013. 6.ed. Serviço Brasileiro de Apoio às Micro e Pequenas Empresas; Departamento Intersindical de Estatística e Estudos Socioeconômicos. Brasília (DF): DIEESE, 2013.

SOLOMON, Michael. O comportamento do consumidor: comprando,

possuindo e sendo. 7. ed. Porto Alegre: Bookman, 2008. 